\title{
A TRAVESSIA DAS PEDRAS NA OBRA DE ALBERT CAMUS
}

\author{
Camila de Castro Diniz Ferreira*
}

RESUMO:

\begin{abstract}
Esta tese, que tem como objetivo chegar ao movimento da escritura de Albert Camus, através da travessia da metāfora pedra, parte dos escritos de juventude do autor em questão, como embrião da problemática que irá suscitar em toda sua obra: um pensamento paradoxal, como forma de se chegar a um conhecimento parcial, situado entre dois pólos opostos, sem jamais permanecer num dos extremos.
\end{abstract}

PALAVRAS-CHAVE: pedra, escritura, pensamento, paradoxo, metāfora.

Uma das razões que pode levar alguém a desejar conhecer a obra de um escritor, imaginar sua vida, viajar para os locais por onde passou, na tentativa de ter os mesmos sentimentos que o marcaram, penetrar em sua escritura, ouvir suas vozes e silêncios e, enfim, construir uma leitura de sua obra, extraindo significantes que mais o tocaram, é a forma como o escritor consegue, através das imagens criadas, transformar sua vida, sua visão de mundo, em palavras ou signos.

Contudo, há várias portas para se chegar ao tecido escritural de um escritor. No meu caso específico - acredito que o mesmo ocorreu a vários leitores de Camus - a porta de entrada para a escritura camusiana foi 0 estrangeiro.

Com uma escritura seca e 1 impa, nua e crua constituída de frases medidas com a exatidão dos silêncios que a povoam, Camus criou, na personagem de Mersault, o mundo do absurdo, surdo aos apelos dos homens. Inocente, o protagonista recusavase a aceitar os jogos impostos pela sociedade, tornando-se, aos olhos de todos, um estrangeiro, ao mesmo tempo que os outros homens the eram estrangeiros.

* Doutora em Letras: Poéticas da Modernidade (Área de concentração: Literatura Comparada), 2004. 


\section{EM TESE}

Belo Horizonte, v. 9, p. I-28I, dez. 2005

Toda essa desmedida entre os anseios do homem e um mundo que the é indiferente, exige uma lucidez que permitiu a Camus olhar o avesso desse mundo absurdo, viver cada instante em sua plenitude, na libertinagem do sol, do mar, do Mediterrâneo e reviver, na lembrança, momentos que serão eternos, porque guardados na imobilidade do tempo: um tempo sem tempo. Talvez esteja, aí, o fascínio que Camus exerce sobre seus leitores.

Se seu amor à vida e aos homens o impulsionou a exercer diversas atividades, desde o jornalismo ao teatro - onde fazia questão de, não apenas escrever as peças, mas dirigi-las e, muitas vezes, participar como ator - e a escrever em diversos gêneros literários, ensaio, romance e dramaturgia, essa mesma diversidade é desafiadora para o leitor que decide debruçar-se sobre sua obra.

Albert Camus é um escritor francês, nascido na Argélia, pouco lido no Brasil, por ter sido marcado profundamente pelo contexto europeu do "entre-guerras", o que, talvez, afaste-nos, a nós, brasileiros, dos conflitos, problemas e interesses que fundamentaram sua vida, sua obra, seu sentimento e seu pensamento.

Entretanto, apesar do contexto familiar em que viveu, em meio à miséria, na Argélia, durante sua infância e adolescência, e dos choques sócio-políticoeconômicos provocados pelas duas guerras mundiais - os dois vetores que marcaram decisivamente sua visão de mundo - sua obra, ao mesmo tempo que traz uma particularidade capaz de produzir uma grande admiração em seus leitores, particularidade esta marcada pelo contexto em que viveu, supera e ultrapassa, em sua escritura, este mesmo contexto do qual se originou.

Não nos esqueçamos de que, em 1940, a França foi derrotada pelas tropas de Hitler, fato que Camus vivenciou, ainda em Argel e, que, juntamente com o conhecimento sócio-político-econômico da situação de seu país, colônia da França, com a qual travava lutas, inclusive internas, por sua independência, foram decisivos para que Camus tomasse um rumo político oposto a de seus companheiros existencialistas, como o de Sartre, por exemplo, recusando-se a pertencer ao Partido Comunista, o que The valeu críticas contundentes de jornalistas e do autor de $A$ náusea, na polêmica em torno da revista Temps modernes (Tempos modernos) da qual era editor.

Foi, sem dúvida alguma, uma posição solitária, mas, acima de tudo, corajosa, pois Camus não se rendeu jamais a nada no qual não acreditava, permanecendo 
fiel, durante toda sua vida, a sua verdade. Passado mais de meio século, os tempos mostraram que ele estava com a razão. Não por acaso, seu livro, 0 homem revoltado, publicado em 1951 e, esquecido, mesmo na França, por algumas décadas, volta a ser lido e discutido neste país, com todo o vigor que merecia, após o atentado de 11 de setembro de 2001, aos Estados Unidos e à invasão deste país ao mundo muçulmano.

Com 0 estrangeiro e 0 mito de Sísifo, publicados em 1942, inicia-se um amplo projeto que, partindo do ciclo do absurdo, estender-se-ia a outros dois ciclos, o da revolta e o do amor, cada um constituído de três gêneros literários: ensaio, romance e dramaturgia, ficando o último ciclo incompleto, devido à morte prematura de Camus, em 1960. Do ciclo do amor, tem-se apenas o romance inacabado, o primeiro homem cujo esboço encontrava-se no carro, por ocasião do acidente que provocou sua morte.

A injustiça metafísica da qual o homem não pode se esquecer, pois que se esquecida degenera em violência e assassinato é, ainda, uma questão individual, de cada ser humano cuja tarefa é ter a lucidez de que, sendo a vida o maior valor, é preciso aceitar - o que não significa resignar-se passivamente - o divórcio entre o homem e o mundo sempre surdo a seus anseios e apelos.

Diante dessa injustiça metafísica, Camus prova, em 0 mito de Sísifo que, apesar do suicídio constituir-se no "único problema filosófico verdadeiramente sério", constatação com a qual inicia o livro em questão, pois trata-se de um julgamento de valor - a vida vale a pena ser vivida diante da injustiça metafísica? - o suicídio não se sustenta diante do raciocínio absurdo. 0 que se percebe é um nihilismo particular e individual que, em última instância, nega qualquer moral e ética necessárias ao reconhecimento do único valor verdadeiro que é a vida.

Não é por acaso que a questão do julgamento, ou seja, da reflexão sobre a moral, particular em cada homem, reaparecerá em 0 estrangeiro, como o avesso de O mito de Sísifo. Aī há a recusa do julgamento por parte da personagem Mersault, devido ao assassinato involuntário provocado pelo sol cujo brilho ofuscou-lhe os olhos. Assim, Camus começa, em 0 estrangeiro, a refletir, não apenas sobre a questão da moral, mas da verdadeira liberdade do homem, aquela que o impede de aceitar as regras impostas pela sociedade cujos valores constituem uma negação da vida. 


\section{EMTESE}

Belo Horizonte, v. 9, p. I-28I, dez. 2005

Chegar ao ciclo da revolta representado pelo Homem revoltado - ensaio-, $A$ peste - romance - e Os justos e 0 estado de sítio - dramaturgia - implica fazer um mergulho no absurdo, pois que a proposta de Camus é passar de uma questão particular de cada ser humano, à necessidade de uma moral cujo maior valor é a vida para a reivindicação de uma ética capaz de envolver todos os homens. Uma questão geral - e não uma generalidade - que reflete sobre o assassinato em massa justificado pelas ideologias totalitárias de esquerda e de direita.

No final de 0 homem revoltado, Camus anuncia "o pensamento do meio-dia", infelizmente traduzido para o português como o "pensamento mediterrâneo", o que retira toda a ambigüidade do termo: "pensamento do meio-dia" é também "o pensamento mediterrâneo", oriundo de uma determinada região, mas é sobretudo o pensamento que se situa entre o "meio-dia", o pensamento do mediterrâneo, marcado pelo sol, pela luz e pela limpidez e "o pensamento da meia-noite", oriundo do norte da Europa, o pensamento sombrio, identificado pela escuridão e pela ausência de esperança na vida.

"0 pensamento do meio-dia", aporia que poderia sintetizar todo o pensamento camusiano - o pensamento entre o sim e o não - é aquele que, recusando-se a permanecer entre dois pólos extremos, permanece entre os dois, numa tensão que, ao invés de encontrar um porto seguro capaz de ancorar as idéias, insiste na mobilidade, na insegurança e na instabilidade de um mundo que Camus construiu para si, enfrentandoo até sua morte, em 1960. Na frase que termina 0 homem revoltado, Camus diz: "0 arco se verga, a madeira geme. No auge da tensão, alçará vôo, em linha reta, uma flecha mais inflexivel e mais livre" (Camus: 1996), anunciando, assim, uma possível liberdade fundamentada numa ética capaz de libertar o homem, através da revolta, das amarras extremistas dos pensamentos totalitários.

Contudo, a questão que resta ao leitor, após o mergulho em sua escrita já madura, é a que se refere ao começo de sua obra e as motivações que o levaram a optar por ser um escritor e não um filósofo, como afirmara diversas vezes. Um começo do começo que se encontra em seus Escritos de juventude.

Não há dúvida de que é sempre um risco analisar obras cujo valor literário não é prioritário, obras que são ainda exercícios de escritura em que o autor, sem ocultar suas dúvidas e receios, busca encontrar seu caminho de escritor. 
Por outro lado, sem esse percurso, muitas vezes errático e hesitante, Camus não teria chegado ao escritor que é, a partir de 0 estrangeiro e 0 mito de Sísifo, não por acaso denominados por ele, "o ponto zero" de sua obra, que deu origem, após a leitura de 0 estrangeiro, feita por Roland Barthes, a 0 grau zero da escritura. Num de seus Cadernos, Camus anota: "0 estrangeiro é o ponto zero. Id. 0 Mito. A Peste é um progresso, não do zero para o infinito, mas para uma complexidade mais profunda que resta definir" (Camus, 1964).

Apesar de uma bibliografia tão ampla e diversificada sobre os ciclos do absurdo e da revolta, quase nada se falou sobre seus Escritos de juventude: há apenas dois livros publicados: o de Paul Viallaneix, O primeiro Camus seguido de Escritos de juventude d'Albert Camus, e um outro, em italiano, chamado A serpente e a sirene, de Corrado Rosso. Não poderia deixar de mencionar também a tradução para o italiano de As vozes do quarteirão pobre e outros escritos juvenis, que, embora não se trate de uma análise, tem o mérito de permitir que este ensaio se tornasse conhecido numa outra língua.

Mesmo 0 avesso e o direito - sobretudo o prefácio escrito por Camus para a reedição, em 1958, pela Editora Gallimard - e Núpcias que são bastante citados em livros que se dedicam à análise dos ensaios camusianos não constituem uma fonte de reflexão com exclusividade, ou seja, sem a junção com outras obras, temas de teses ou livros.

Além da trajetória das pedras, na obra de Camus, que se inicia em Núpcias, outras metáforas mais explícitas chamam a atenção do leitor, como por exemplo, a importância do sol, tema amplamente explorado em diversos estudos. Roger Grenier escreveu o importante estudo, Albert Camus, sol e sombra, uma biografia intelectual e Karl W. Modler fez uma tese que, transformada em livro, Sol e medida na obra de Albert Camus (2000), faz uma análise profunda e exaustiva sobre a relação entre sol e medida, onde argumenta que, seria quase incompreensível o fato de ninguém ter, ainda, percebido esta ligação.

Tem razão Modler quando, ao optar pela análise da simbologia do sol em relação ao conceito de medida em Camus, diz na introdução de seu livro, Sol e medida na obra de Albert Camus: "Este estudo não teria outra solução senão a de propor um 


\section{EM TESE}

Belo Horizonte, v. 9, p. I-28I, dez. 2005

novo 'dizer' ao 'tudo foi dito" para invocar - com Camus - esse espaço que é a criação e a escritura."(Modler: 2000, 9).

É possível buscar um novo olhar, um "novo dizer" sobre o "tudo foi dito", através da "travessia das pedras", sobretudo quando se depara com a imensa fortuna crítica da obra camusiana. A "travessia das pedras" permite escapar das generalidades ditas e reditas, estudadas e reestudadas à exaustão, uma vez que se trata de um aspecto particular da obra de Camus, ainda não analisado.

A pedra impulsiona os movimentos da escritura camusiana, na medida em que se abre um leque de significações, fato que contribuiria de maneira significativa para a compreensão de sua obra, inclusive, para aquelas que vieram depois de uma forma mais consistente, constituindo os dois ciclos, o do absurdo e o da revolta.

Sendo o começo e o fim, o que significa não ser nada e tudo simultaneamente, pois a pedra apenas é, representando paradoxalmente toda a trajetória entre o começo e o fim - o meio, portanto -, ao se constituir na radicalização da "estrangeiridade" do homem em relação a si mesmo e à sociedade em que vive, estaria não apenas relacionada à "medida", necessária para a lucidez frente ao absurdo, mas ao "pensamento do meio-dia", aporia que nasce diretamente dos conceitos de "medida" e de "limite", ou seja, aqueles que impõem a necessidade de não se fixar nos extremos e em radicalizações, mas de permanecer entre eles.

"A travessia das pedras" conduz, assim, aos movimentos da escritura camusiana em suas diversas significações, desde os Escritos de juventude, de Albert Camus e 0 avesso e o direito, como forma de introdução ao reino das pedras, ao núcleo da travessia na escritura que se encontra em Núpcias e em 0 verão até 0 mito de Sísifo em que a pedra torna-se a pedra filosofal do absurdo. Já num contexto estritamente religioso e místico, "a pedra que cresce", conto nascido da viagem de Camus com 0swald de Andrade a Iguape, por ocasião de sua visita ao Brasil, em 1947, representa uma outra aporia camusiana, imprescindível para sua compreensão: "É preciso ser solitário e solidário". Em outras palavras, a ética não pode prescindir da estética e nem esta da ética. 
RÉSUMÉ:

Cette étude, qui a pour but arriver à la demarche de l'écriture d'Albert Camus, en étudiant la traversée de la métaphore pierre, commence par les écrits de jeunesse de l'auteur étudié, origine de la problématique qui traverse toute son oeuvre: une pensée paradoxale, située entre deux pôles em opposition, sans jamais rester sur les extrêmes.

MOTS-CLÉS: pierre, écriture, pensée, paradoxe, métaphore.

\section{REFERÊNCIAS BIBLIOGRÁFICAS}

CAMUS. Albert. Carnets II (jan. 1942-mars. 1951). Paris: Gallimard, 1964.

CAMUS, Albert. Diário de viagem. A visita de Camus ao Brasil. Trad. Valérie Rumjanek. Rio de Janeiro: Record, 1978.

CAMUS, Albert. Essais. Paris: NRF/ Gallimard, Bibliothèque de la Pléiade, 1985.

CAMUS, Albert. 0 avesso e o direito. Trad. Valérie Rumjanek. Rio de Janeiro: Record, 1999.

CAMUS, Albert. 0 exílio e o reino. Trad. Valérie Rumjanek. Rio de Janeiro: Record, 1997.

CAMUS, Albert. O primeiro homem. Trad. Teresa Bulhões carvalho da Fonseca; Maria Luisa Newlands Silveira. Rio de Janeiro: Nova Fronteira, 1994.

CAMUS, Albert. Théâtre, récits, nouvelles. Paris: NRF/ Gallimard, Bibliothèque de la Pléiade, 1962.

GAY-CROISIER. Albert Camus, L'homme révolté cinquante ans après. Paris: La Revue des letttres modernes, 2001.

GUÉRIN, Jeanyves. Portrait de l'artiste em citoyen. Paris: François Bourin, 1993.

MODLER, Karl W. Soleil et mesure dans l'oeuvre d'Albert Camus. Paris: L'Harmattan, 2000.

VIALLANEIX, Paul. Le premier Camus suivi de Écrits de jeunesse d'Albert Camus. Paris: Gallimard, 1973. (Collection Cahiers Albert Camus II).

VIRCONDELET, Alain. Albert Camus, Vérité et légendes. Paris: Éditions du Chêne, 1998. 